\title{
Analysis of Team Learning Experiences and Educational Outcomes in Robotics
}

\author{
David J. Ahlgren ${ }^{1} / \operatorname{Igor~M.~Verner~}^{2}$ \\ Trinity College/Technion-Israel Institute of Technology
}

\begin{abstract}
This paper argues that educational research, which assesses learning and instruction in introductory robotics courses, is essential to the evaluation, improvement, and dissemination of robotics programs. The authors consider their experiences in teaching robotics as an introductory engineering subject at Trinity College in the United States, and as a graduation project course at the Mevohot E'ron High School in Israel. Both programs focus on team-based design of fire-fighting mobile robots to compete in the Trinity College Fire-Fighting Home Robot Contest. For these courses we discuss educational objectives, course content and organization, learning activities, and educational outcomes.
\end{abstract}

\section{Introduction}

There is a rapidly growing literature on robotics as an instructional medium in university and secondary school education with a main focus on describing initiatives, courses, and instructional tools. However, limited progress has been made in the conceptualization of learning and instruction processes that underlie successful introductory robotics courses. Important open questions relate to prerequisite knowledge, integrated curriculum, learning by design and teamwork, robotic competitions, assessment, and evaluation. Finding answers to these questions requires educational research, which will help improve teaching and offer the means to evaluate and disseminate robotics programs. To achieve these goals, the educational research should thoroughly examine possible curricular models and team learning experiences in order to optimize educational outcomes of the robotics course. This includes studying educational features of robotic competitions, which can significantly stimulate learning motivation of students, and intensify the learning process.

In this paper the authors consider their experiences in teaching robotics as an introductory engineering subject at the university and high-school levels in the United States and in Israel. Examples include a first-year engineering design course at Trinity College and a high-school course at Mevohot E'ron in Israel. Both focus on team-based design of firefighting mobile robots to compete in the Trinity College Fire-Fighting Home Robot Contest. For these courses we discuss educational objectives, course organization, outline, learning activities, and educational outcomes. Special attention is paid to assessment of team learning experiences in designing, building and operating robot systems. Our case studies showed that a commonly used assumption on homogeneous prerequisites, learning activities, progress, motivation and attitudes of students in teams is not valid in the introductory robotics course at Trinity College. Therefore educational outcomes of the course cannot be evaluated using only average statistical rates. We discuss findings of educational assessment and point out on possible improvements in the introductory robotics course.

\footnotetext{
${ }^{1}$ Department of Engineering, Trinity College, Hartford, Connecticut 06106. dahlgren@trincoll.edu

${ }^{2}$ Department of Education in Technology \& Science, Technion - Israel Institute of Technology, Haifa, 32000, ISRAEL. ttrigor@tx.technion.ac.il
} 


\section{Fire-Fighting Robot Contest}

The Trinity College Fire-Fighting Home Robot Contest (TCFFHRC) aims to increase awareness of robotic fire-fighting, encourages team-based education, and promotes robotics as a theme for teaching engineering design. The TCFFHRC is open to persons of all ages, affiliations, and levels of skill. The TCFFHRC's objective is to design a robot, which can autonomously navigate through a maze, find a lit candle, and extinguish it in the shortest time. The maze, known in advance, has four rooms and connecting hallways (Figure 1). The candle is placed at random in one of the four rooms, and the robot must navigate to within 12 " of the flame before putting it out. The score is the sum of the fastest two run times of the allowed three runs. Deductions are given for reliability, obstacle avoidance ability, starting at an arbitrary location, and non-dead reckoning operation [1-3].

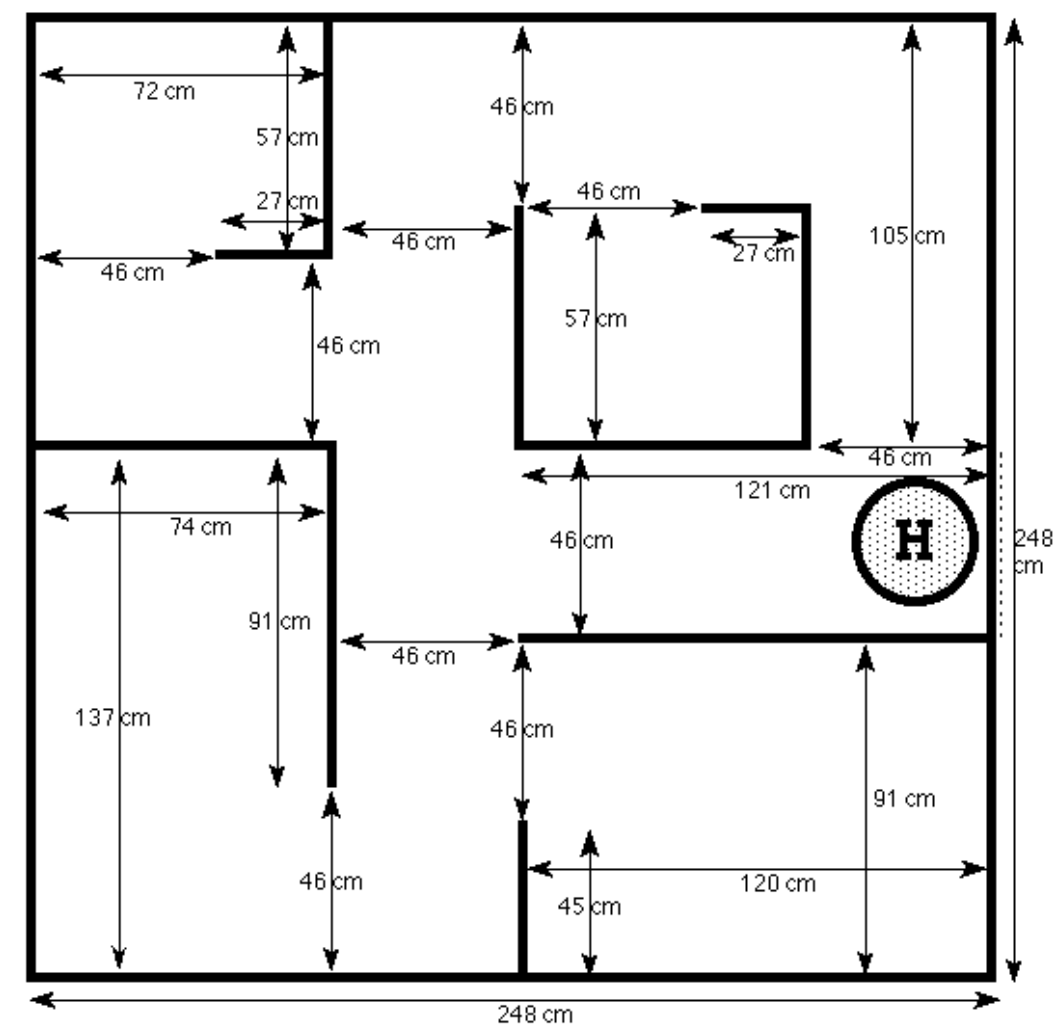

Figure 1. Fire-Fighting Contest Maze

The 133 robots entered in the 2001 contest on the Trinity College campus in Hartford demonstrated the creative efforts of more than 400 designers including persons from the People's Republic of China, South Korea, Israel, France, Romania, and Argentina. More than sixty universities have competed. The contest has four divisions: Junior (9th grade and under), High School (grades 9-12), Senior (university students, other adults) and the new Expert division. Expert Division robots must be able to avoid obstacles, navigate without dead reckoning, and start from an arbitrary starting position. In 2001, there were 12 entries in the Junior Division, 36 in the High School Division, 36 in the Senior 
Division, and 5 in the Expert Division. A full description of the TCFFHRC may be found on the Web at http://www.trincoll.edu/events/robot/.

\section{Trinity College Experience}

Trinity is a highly selective four-year undergraduate college that has offered engineering instruction in a liberal arts setting for over one hundred years. Trinity's engineering program is accredited under the new ABET criteria. Design of autonomous robots, motivated by the TCFFHRC, has enhanced the Trinity engineering curriculum in three areas: (1) a new design course for first-year students; (2) a robot study seminar; and (3) senior design projects. Each of these is described below.

\section{First-Year Design Course}

This new course, ENGR 120: Introduction to Engineering Design--Mobile Robotics, has been offered twice, with a total enrollment of 40 students. Course objectives include: (1) introduce students to the field of engineering; (2) offer hands-on laboratory assignments; (3) present engineering design from philosophical and professional perspectives, through readings (e.g., Petroski [4]); (4) offer students the opportunity to evaluate engineering as a major field; (5) develop basic engineering skills including programming, use of lab instruments (oscilloscope, signal generator, voltmeter), use of CAD packages for mechanical and electrical design, and real-time data acquisition; (6) introduce basic techniques in robotics including motor control (PWM, PD/PID, fuzzy logic), microcontroller interfacing, and application of sensors.

Every ENGR 120 student becomes a member of a team that makes a fire-fighting robot. Each team is provided a Lego Mindstorms kit and a popular small computer used widely in educational robotics - the HandyBoard [5]. A series of hands-on workshops introduces students to major problems associated with mobile robot design. Workshop topics include programming in $\mathrm{C}$, sensor interfacing and calibration, motor control, sensor-based navigation, and system integration and test. The course relies on the new text by Fred Martin, "Robotic Explorations-A Hands-On Introduction to Engineering" [6]. A full description of ENGR 120 is presented in Ahlgren [7]. That paper shows that ENGR 120 encourages students to develop core engineering abilities that are reflected in the ABET outcomes a-k [8].

\section{Robotics Study Team}

The second curricular locus for robotics at Trinity is the Robotics Study Team (RST), which was organized in 1995 in order to compete in the TCFFHRC. RST robots have taken second (1997) and first (1998) places in the TCFFHRC Senior Division, second place in the Senior Division of the 2000 Middle East Fire-Fighting Home Robot Contest, second place (robot MiniBob, Figure 2) in the Expert Division of the TCFFHC (2001), and eighth place in the 2001 International Ground Vehicle Competition (IGVC) (robot ALVIN II, Figure 3) [9]. The Robotics Study Team includes students from all four college years. Its members, about ten each semester, receive independent study credit and make a seminar presentation every week. The RST attracts students primarily from engineering and computer science, but the membership has included persons majoring in the humanities, arts, or social sciences. Each student joins a disciplinary group (electronics, mechanics, software, or sensors) that provides the team specific expertise. Team members work in the Robot Engineering Laboratory, which is open to students 24 hours/day. Projects underway include the following: 
- Improvement of IR and ultrasonic sensor arrays for maze navigation

- Refinement of fuzzy-based maze navigation algorithms

- Development of a "smart" miniature camera for robotics

- Development of ALVIN III, an autonomous land vehicle to compete in the 2002 IGVC

- Development of walking robots to compete in the TCFFHRC

- Development of versatile, easily employed servo motor controllers

\section{Senior Design Projects}

Motivated by the opportunity to compete in the TCFFHRC and the IGVC, senior engineering students at Trinity have carried out more than 15 senior design projects in robotics over the last several years. Projects have included the design of the following: a capacitive proximity sensor, microcontroller-to-DSP interface, DC motor controllers, vision system for mobile robotics, ultrasonic ranging system, and the autonomous land vehicle ALVIN I which competed in the 2000 IGVC.

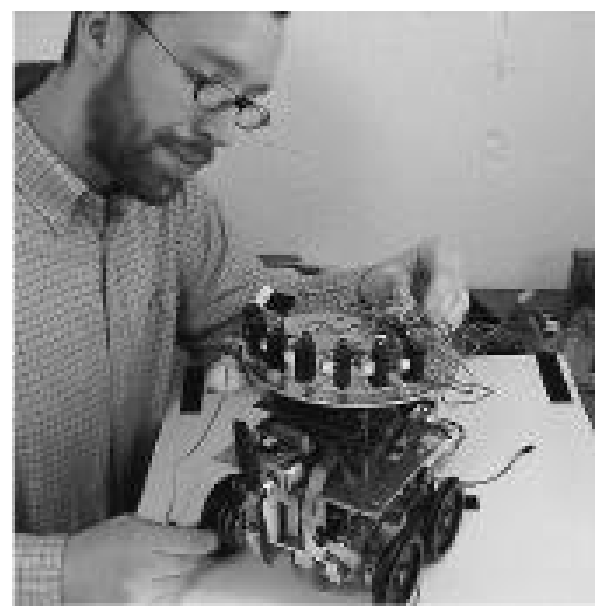

Figure 2. Trinity RST Student Building MiniBob's Sensor Array

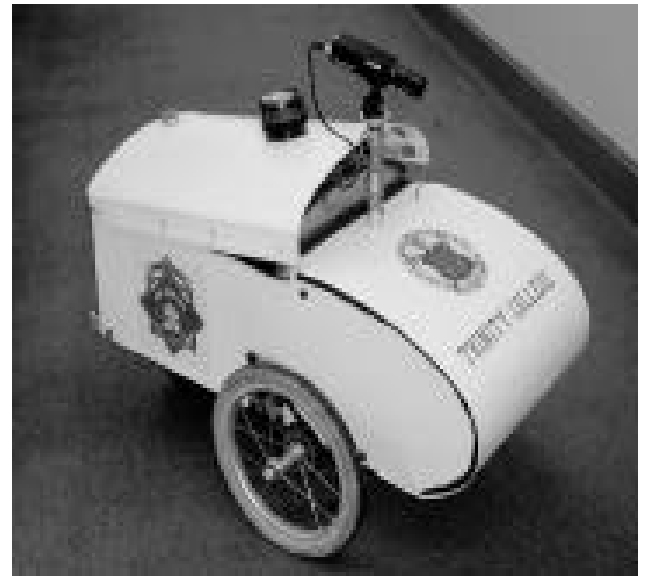

Figure 3. RST Autonomous Land Vehicle ALVIN II

\section{Design and Technology in High Schools—Experiences in Israel}

Fire-fighting autonomous robot design has served as the theme for graduation projects for advanced high-school science students in several countries. Since the 1998-99 school year high-school students in Israel have participated in TCFFHRC and in the local firefighting robot contest organized by the Israeli Ministry of Education. The Israel delegation at the TCFFHRC included 24 students from five schools in 1999, 73 students from seven schools in 2000 and 81 students from seven schools in 2001. This experience serves as an impressive example of how to integrate robotics into the high-school curriculum with the support of the national school system [10]. The graduation project is taught in grade 12 as an optional matriculation subject connected with one of science, technology, or humanities disciplines. Graduation projects in robotics are connected with the three technology education disciplines: Machine Control, Electronics, and Information Systems Technology. Each of these disciplines is an optional matriculation subject studied in the eleventh and twelfth grades. The disciplines have been authorized and accredited by the Israeli universities among the six preferred matriculation subjects. A more detailed description of the Machine Control discipline is given in Verner and Betzer [11]. 
A growing number of high schools are now developing curricula and carrying out projects related to the fire-fighting contest. As an example, we consider a fire-fighting robot project, which is been carried out at the Mevohot E'ron high school. In 1998 one of the teachers, Eyal Hershko, started his graduate studies at the Technion with thesis research in educational robotics. He has developed a fire-fighting project in his school since 1999, with Dr. Verner serving as project consultant and research supervisor. The study of Talrick and Rug Warrior robot kits, the user manuals and the text [12] was an important initial step of the project activities. This experience helped the teacher and the students to acquire knowledge on mobile robots, recognize problems to be solved, and develop their own fire-fighting robot.

The Mevohot E'ron robot team in 1999-2000 consisted of 13 students. The team was divided into five groups: structure, sensors, fire extinction, software and management. The structure group designed and built the robot structure, considering carefully the location of the center of gravity and the need to reduce robot weight. The sensors group dealt with calibration of sensors and real motors and with the kinematics of robot straight and circular motion. The fire extinction group examined several possible solutions for extinguishing candles, chose a suitable propeller device, and mounted and tested it on the robot. The software group dealt with maze navigation logic and programming robot movements. The management group coordinated the project schedule, logistics, reports, and presentations. The team participated in the TCFFHRC 2000 and shared places 12 to 16 (among 48 in the junior division).

As a result of the project evaluation study, several improvements were made in the curriculum of 2000-2001. The team included 8 students divided into 2 groups of equivalent amount of project work and responsibilities: structure and fire extinction $(\mathrm{S} \& \mathrm{FE})$, and sensors and software $(\mathrm{S} \& \mathrm{~S})$. The $\mathrm{S} \& \mathrm{FE}$ group examines a number of alternative variants of the robot structure and fire extinction by means of physical and mathematical modeling, and CAD. The S\&S group deals with robot XY kinematics, application of shaft encoders for the position control, and algorithms and software for maze navigation. The team developed another fire-fighting robot, which took seventh place (among 36) in the 2001 Trinity contest. The ongoing 2001-2002 project involves 25 students divided into three teams, who work on 3 new and different fire-fighting robots.

\section{Assessment of the 2001 TCFFHRC}

Educational surveys were administered at the 1999-2001 fire-fighting contests at Trinity, to assess learning outcomes of contest-oriented curricula and attitudes of the participants. At each survey cycle the contestants were asked to complete new survey forms. An incremental survey method was applied in which each new survey cycle added knowledge to that previously found.

In 2001 answers were obtained from 243 respondents out of 407 registered for the contest, a higher response than in 1999 and 2000 (respectively 112 and 123 respondents). Of those who responded to the 2001 survey, 94 (39\%) were university students, $90(37 \%)$ were high school students $(37 \%), 32(13 \%)$ were middle school students, $23(9 \%)$ were working engineers, and $4(2 \%)$ were instructors. Respondents among university students were 21 freshmen, 15 sophomores, 15 juniors, 33 seniors, and 10 graduate (M.S.) students. The survey data were observed from different perspectives and were useful in used to characterize learning outcomes for various groups of learners, particularly the Trinity ENGR 120 students. 
The 2001 TCFFHRC survey sought the following information:

1. Forms of participation in the robot contest program;

2. Motivation for participation in the robot contest program;

3. Prior knowledge;

4. Involvement of ENGR students in development of robot subsystems;

5. Advancement in theoretical and practical knowledge;

6. Attitudes of ENGR 120 students.

Representative results are presented below.

1. Forms of participation. Participants were asked to choose from the following list: part of a course, graduation project, extracurricular activities, and hobby. The answers of undergraduate students, in percentages, are given in Table 1 . The data indicate the following:

a) That most first-year students in the TCFFHRC participate as part of a formal course. ENGR 120 is one such course.

b) Most juniors and seniors participate as part of a graduation design project.

c) Sophomores, who may have completed a first-year course and who are not yet concerned about defining graduation projects, participate mainly out of personal interest.

Table 1. Forms of participation in the 2001 TCFFHRC (\%)

\begin{tabular}{|lcccc|}
\hline \multicolumn{1}{|c}{ Forms } & Fresh & Sophomore & Junior & Senior \\
\hline Part of the course & 76 & 14 & 33 & 29 \\
\hline Graduation project & 0 & 0 & 40 & 43 \\
\hline Extracurricular activities & 33 & 93 & 33 & 20 \\
\hline Hobby & 29 & 43 & 20 & 24 \\
\hline
\end{tabular}

2. Motivation for participating in the TCFFHRC. Undergraduates were asked to express levels of motivation on the following scale: "very important", "important", "somewhat important", "not important". Table 2 lists percentages of responses in either the "very important" or "important" ranges. 
Table 2. Motivation for Participating in the 2001 TCFFHRC (\%)

\begin{tabular}{|lccccc|}
\hline \multicolumn{1}{|c}{ Motivation factors } & ENGR 120 & Fresh & Soph. & Jr. & Sr. \\
\hline $\begin{array}{l}\text { 1. A positive attitude towards robotics and } \\
\text { project-based learning }\end{array}$ & 100 & 90 & 88 & 100 & 86 \\
\hline $\begin{array}{l}\text { 2. Awareness of the practical need of knowledge } \\
\text { acquired through participation in the contest }\end{array}$ & 70 & 74 & 88 & 100 & 75 \\
\hline 3. Prizes, travel, grants & 10 & 11 & 0 & 31 & 14 \\
\hline 4. Enjoyment of robot gaming & 60 & 58 & 63 & 88 & 31 \\
\hline $\begin{array}{l}\text { 5. Eagerness to cope with the contest challenges } \\
\text { and win a reward }\end{array}$ & 40 & 47 & 56 & 75 & 61 \\
\hline $\begin{array}{l}\text { 6. Opportunity to develop and apply your own } \\
\text { ideas }\end{array}$ & 90 & 95 & 94 & 94 & 97 \\
\hline 7. Interest in earning a high course grade & 20 & 53 & 6 & 31 & 67 \\
\hline 8. Demonstration of professional skills & 50 & 53 & 63 & 75 & 77 \\
\hline
\end{tabular}

The data indicate the following:

a) A high level of learning motivation among all respondents.

b) The most important motivating factor for undergraduates is the opportunity to apply their own ideas.

c) Interest in receiving a high course grade is most evident in the senior year, likely indicating high interest in achieving success on senior design projects. First year students, enrolled in their first engineering course, rank second in this category.

d) Sophomores and juniors are the most interested in acquiring practical knowledge through contest participation.

e) Importance of demonstrating professional skills grows as students progress through their undergraduate years.

f) Prizes and travel grants are not strong motivators.

g) Motivation of the Trinity ENGR 120 students reflected that of the whole group of first-year students, except for course grades, which was less important for them.

3. Prior Knowledge. All participants were asked to rate their prior knowledge in 15 subject areas related to robot development. Responses of the ENGR 120 students who participated in the 2001 contest $(\mathrm{N}=10)$ are presented in Table 3 . The data do not fully reflect that student background was nearly heterogeneous in this sample and that no gender differences were found. 
Table 3. Fraction of ENGR 120 Students with Prior Knowledge

\begin{tabular}{|lcc|}
\hline \multicolumn{1}{|c}{ Subject Area } & Theory & Practice \\
\hline Electronics & 0.6 & 0.3 \\
\hline Computer communication & 0.4 & 0.2 \\
\hline Microprocessors & 0.2 & 0.2 \\
\hline Assembly language & 0.5 & 0.2 \\
\hline High-level language & 0.5 & 0.6 \\
\hline Motors \& gears & 0.9 & 0.7 \\
\hline Mechanical design & 0.7 & 0.4 \\
\hline Sensors & 0.1 & 0.1 \\
\hline Data analysis & 0.8 & 0.6 \\
\hline Physical fields & 0.5 & 0.4 \\
\hline Mathematical modeling & 0.6 & 0.5 \\
\hline Control & 0.3 & 0.4 \\
\hline CAD tools & 0.1 & 0.1 \\
\hline Systems design & 0.4 & 0.5 \\
\hline Teamwork & 1.0 & 0.8 \\
\hline
\end{tabular}

Findings from Table 3 include:

a) Few students had backgrounds in computer communication, microprocessors, sensors, control, systems design, or CAD.

b) Non-US students had stronger backgrounds in electronics, data analysis, physical fields, and mathematical modeling. Stronger technical preparation of non-US students was evident.

c) Experience with team-based learning was evident among nearly all students.

4. Involvement of ENGR 120 Students in Development of Robot Subsystems. The ENGR 120 design teams were free to assign responsibilities to team members. It was possible that some team members would focus their efforts on one or two robot subsystems. Table 4 shows the fraction of students who participated in developing each subsystem; categories of development were "design", "construction", "test", and "improvement". These data lead to the following observations:

a) Almost all students engaged design, construction, testing, and improvement of drive mechanisms, mechanical structure, and sensor systems.

b) Since most of the microcontroller and control circuitry was provided to students in form of HandyBoard and Lego motor components, students did not design these components. They did, however, test and improve these subsystems.

c) Only about one-half of students engaged in software development and construction. Slightly greater involvement in software testing and improvement was evident. 
Table 4. Fraction of ENGR 120 Students Participating in Robot Subsystems

\begin{tabular}{|lcccc|}
\hline \multicolumn{1}{|c}{ Subsystems } & Design & Construct & Test & Improve \\
\hline Drive mechanism & 1.0 & 0.7 & 0.9 & 0.9 \\
\hline Mechanical structure & 0.8 & 0.9 & 0.9 & 0.8 \\
\hline Micro-controller & 0.2 & 0.3 & 0.6 & 0.8 \\
\hline Control circuits & 0.3 & 0.5 & 0.8 & 0.8 \\
\hline Sensor system & 0.8 & 1.00 & 1.0 & 1.0 \\
\hline Steering planning & 0.7 & 0.8 & 0.9 & 0.9 \\
\hline System software & 0.5 & 0.6 & 0.7 & 0.6 \\
\hline Extinguishing device & 0.5 & 0.6 & 0.8 & 0.9 \\
\hline
\end{tabular}

5. Advancement in theoretical and practical knowledge. Students were asked to rate their advancement in the 15 subject areas. Table 5 lists results for the ENGR 120 students who entered the 2001 TCFFHRC entrants.

Table 5. Students Advancing in Subjects Due to ENGR $120(\%)$

\begin{tabular}{|ccl|}
\hline Theory & Practice & \multicolumn{1}{c|}{ Subjects } \\
\hline 100 & 100 & $\begin{array}{l}\text { Electronics, computer communication, motors } \\
\text { and gears, mechanical design, control, sensors }\end{array}$ \\
\hline 90 & 100 & Systems design \\
\hline 90 & 89 & Microprocessor, high-level language \\
\hline 90 & 78 & Mathematical modeling \\
\hline 80 & 89 & Data analysis, teamwork practice \\
\hline 60 & 67 & CAD tools \\
\hline 60 & 44 & Physical fields \\
\hline 60 & 22 & Assembly language \\
\hline
\end{tabular}

Observations:

a) Almost all students reported progress in eight areas central to design of autonomous mobile robots (electronics, computer communication, motors and gears, mechanical design, control, sensors, and system design.)

b) Most students reported progress in high-level languages, data analysis, mathematical modeling, and use of CAD tools.

c) Lower progress was reported in physical fields and assembly language. The course did not focus on these topics.

5. Attitudes of ENGR 120 students. Developed attitudes of ENGR 120 students were surveyed with respect to the following categories: "Interest in designing, building and operating robot systems," "Interest in learning science and technology subjects," "Interest in entering an advance level engineering program," and "Interest in specializing in robotics." Table 6 indicates the fraction of students indicating the following levels of interest: negative ( $\mathrm{Ng}$ ), no impact (none), limited positive (Lp), and strong positive $(\mathrm{Sp})$. 
Table 6. Attitudes toward Robotics and Engineering

\begin{tabular}{|lcccc|}
\hline \multicolumn{1}{|c}{ Attitudes } & $\mathrm{Sp}$ & $\mathrm{Lp}$ & $\mathrm{None}$ & $\mathrm{Ng}$ \\
\hline $\begin{array}{l}\text { Interest in designing, building and operating } \\
\text { robot systems }\end{array}$ & 0.8 & 0.2 & 0.0 & 0.0 \\
\hline $\begin{array}{l}\text { Interest in learning science and technology } \\
\text { subjects }\end{array}$ & 0.5 & 0.5 & 0.0 & 0.0 \\
\hline $\begin{array}{l}\text { Interest in entering an advanced level } \\
\text { engineering program }\end{array}$ & 0.4 & 0.4 & 0.2 & 0.0 \\
\hline Interest in specializing in robotics & 0.1 & 0.6 & 0.2 & 0.1 \\
\hline
\end{tabular}

Observations from Table 6 include the following:

a) All students reported a positive influence on their interest in developing robots and learning science and technology subjects.

b) Most of the students felt that the course had a positive in entering an advanced level engineering program. A lower percentage indicated interest in specializing in robotics.

c) A minority of students found, through the course, that engineering was not for them.

\section{Conclusions}

We have introduced the Trinity College Fire-Fighting Home Robot Contest and described related curricular enhancements and projects at Trinity College and in Israel. We have presented survey data from the 1999-2001 TCFFHRC events, showing that the contest has motivated progress in theoretical and practical areas among students of all educational levels.

We have focused on survey data for the Trinity College course ENGR 120, which introduces first-year students to engineering design principles using the fire-fighting robotics theme. These, and other undergraduate students, provided data regarding prior knowledge, motivation, progress in robotics-related subjects, involvement in subsystem design, and attitudes.

The contest promoted design by teams; for the contest as a whole, the average team size was just over three persons per design team. Team size in ENGR 120 was three, consistent with the average. Most ENGR 120 students reported a gain in teamwork experience.

Responses from ENGR 120 students clearly indicate strong gains in both theoretical and practical knowledge associated with topics that are central not only to robot design but also to many other engineering areas. Such topics include teamwork, data analysis, mathematical modeling, computer interfacing, motor control, mechanical design, sensors, and CAD. Thus ENGR 120 course also strengthened the skills of students who will not focus on robotics at the upper level of engineering studies.

The data indicate that not all ENGR 120 students participated in software development and so lost an opportunity to build programming skills early in the undergraduate 
experience. This is regrettable since the Trinity Engineering program requires programming proficiency as a graduation requirement. In response to this indication, every ENGR 120 student will be required to demonstrate programming skill in the 2002 course. Despite this failing, the data indicate that ENGR 120 achieve the goal of raising interest in designing and building robots and learning science and technology subjects.

\section{Acknowledgements}

TCFFHRC sponsors include Motorola SPS, Watts Industries, the National Collegiate Inventors and Innovators Alliance, and Charles L. Wilson III. The authors thank Jake Mendelssohn, contest coordinator, and Eyal Hershko, robotics teacher, for their many contributions.

\section{References}

[1] Pack, D.; Mankowski, A.M.; and Freeman, G. J. 1998. A Fire-Fighting Robot and its Impact on Educational Outcomes. In Proceedings of the 1998 ASEE Annual Conference, CD. Washington, D. C.: American Society for Engineering Education.

[2] Avanzato, R. 1998. Collaborative Mobile Robot Design in an Introductory Programming Course for Engineers. In Proceedings of the 1998 ASEE Annual Conference, CD. Washington, D. C.: American Society for Engineering Education.

[3] Verner, I., Ahlgren, D., and Mendelssohn, J. "Fire Fighting Robot Competitions and Learning Outcomes: A Quantitative Assessment." Proc. 2000 ASEE Annual Conference, St. Louis, 2000.

[4] Petroski H. 1996. Invention by Design. Cambridge, Mass.: Harvard University Press.

[5] HandyBoard Web site: http://www.handyboard.com

[6] Martin, F. Robotic Explorations, a Hands-On Introduction to Engineering. Prentice Hall, 2001.

[7] Ahlgren, D. J. "Fire-Fighting Robots and First-Year Engineering Design: Trinity College Experience." Proc. 31st ASEE/IEEE Frontiers in Education Conference, Reno, 2001.

[8] "Criteria for Accrediting Engineering Programs (2001-2002)," Accreditation Board for Engineering and Technology, Inc., Baltimore (http://www.abet.org).

[9] IGVC Home Page: http://www.secs.oakland.edu/SECS_prof_orgs/PROF_AUVSI

[10] Verner, I., Waks, S., and Kolberg, E. "Upgrading technology towards the status of high school matriculation subject: A case study." Journal of Technology Education, 9(1), 1997, 64-75.

[11] Verner, I.; and Betzer, N. Machine Control - A Design and Technology Discipline in Israel's Senior High Schools. International Journal of Technology and Design Education, 11(3), 2001, 263-272.

[12] Jones, J.; Seiger, B.; and Flynn, A. 1999. Mobile Robots, Inspiration to Implementation, 2nd ed. Natick, Mass: A. K. Peters. 